\title{
Adding to the Tapestry
}

\author{
Janet A. Kourany*
}

\begin{abstract}
Kevin Elliott's $A$ Tapestry of Values is a terrific book, chock full of valuable case studies and incisive analyses. It aims to be useful not only to students of philosophy of science and the other areas of science studies but also to practicing scientists, policymakers, and the public at large - a tall order. And it succeeds admirably for many of these folks. In my comments I suggest what it would need for the rest.
\end{abstract}

\section{Keywords}

values in science $\boldsymbol{\bullet}$ democratization of science $\boldsymbol{~ s o c i a l l y ~ r e s p o n s i b l e ~ s c i e n c e ~} \bullet$ pedagogical challenges $\bullet$ John Rawls

Part of an author-meets-critics book symposium on A Tapestry of Values: An Introduction to Values in Science by Kevin C. Elliott (Oxford University Press, 2017), with Elliott 2018a and 2018b, Douglas 2018, and Brown 2018

Kevin Elliott's $A$ Tapestry of Values is a terrific book, chock full of valuable case studies and incisive analyses. Its aim is to turn its readers, even the least experienced among them, into sophisticated observers and participants in the science scene. And while it is geared to the needs of introductory students and the general public, it takes up questions that even scientists and experts in the various fields of science studies will find illuminating and important. Indeed, that was precisely Kevin's intention - to provide enlightenment and guidance to a whole slew of possible readers. Thus, Kevin says in his Preface:

My goal was to incorporate ... philosophical insights into a book that a college freshman or an interested member of the general public could read and find to be helpful and informative. Also, ... I wanted the book to be sufficiently interdisciplinary to be appropriate for introductory courses on science policy, research ethics, history of science, environmental studies, and STS, as well as the philosophy of science. Finally, I wanted the book to be relevant to practicing scientists and policymakers. (Preface, ix)

*Department of Philosophy, 100 Malloy Hall, University of Notre Dame, Notre Dame, Indiana 46556 USA, jkourany@nd.edu

Received 17 July 2018; Accepted 29 July 2018 doi:10.3998/ptpbio.16039257.0010.009 
Now, this is the kind of thing that authors must say to publishers when they are seeking a contract. It is also the kind of thing that publishers must say in their advertisements to college teachers. But in this case, the saying is not the usual mandatory fluff. Kevin does have important things to say to all these folks. It is, however, this feature of his book that gets Kevin into trouble, though it is also this feature that can ultimately make him a star.

Start with Kevin's central message. It is that science is absolutely permeated with values, all kinds of values: ethical values and political values and economic values and cultural values and sometimes even religious values. These values shape:

- the kinds of topics scientists prioritize in their research as well as the kinds of topics outside interests judge deserving of funding;

- the ways these topics are studied; that is, the specific questions scientists raise, the methods they use to answer these questions, and the assumptions they make in the process;

- the particular objectives scientists have in studying these topics, such as the achievement of quick results, or results that don't cost too much, or results that illuminate some aspects of their subject matter even while they leave other aspects in the dark;

- the ways scientists deal with the whole question of uncertainty, such as the amount of evidence they require for particular sorts of conclusions and the amount of confidence they exhibit when they report those conclusions;

- the ways scientists report their conclusions: the kinds of terminology they favor, the categories they employ, their metaphors, and the like.

There is at least one more way in which values shape science, one that Kevin doesn't consider. It concerns the makeup and organization of scientific communities-who is admitted, who has influence, who is marginalized, who is excluded. Women scientists know a lot about this aspect of science, but so do various groups of men, such as African-American men and Hispanic men. And given the interactions of this mode of value-influence with all the others that Kevin does consider, it should be included here too.

Science, then, is permeated with values. In fact, Kevin tells us, science is a tapestry of values, a splendidly woven tapestry rather like the famous unicorn tapestries on display in the Cloisters in New York City's Fort Tryon Park, two blocks away from the home where I grew up. This is Kevin's metaphor, the title of his book, even the picture on its front cover. Of course, science is a tapestry of epistemic values as well as social values, and the two kinds of values are tightly interwoven in the fabric of science. Still, the social values can be analytically separated from the epistemic values, and it is the social values, called by Kevin simply values, that, for perfectly understandable reasons, command the focus of Kevin's attention. It is just here, however, that the pedagogical effects of Kevin's book begin to diverge.

For philosophy students the tapestry of values that Kevin describes is a philosophers' dream. Indeed, this tapestry is rich with a diversity of values. It includes, for example, the value in medical research of prioritizing the health problems of those who can pay for the results of the research as well as the value of prioritizing the health problems of those who are suffering the most (whether or not they can pay). It includes the value in agricultural research of exploiting the methods of the natural sciences in order to develop new techniques helpful to agribusiness (such as genetic engineering of new kinds of seeds and chemical synthesis of new kinds of fertilizers and pesticides) as well as the value of exploiting the methods of the social sciences to develop techniques helpful to small-scale farmers in developing countries (such as better social 
safety nets and better modes of land management and distribution). It includes the value in toxicological research of requiring more extensive and more rigorous evidence to prevent the over-regulation of safe industrial products as well as the value of requiring simpler and quicker assessment procedures to enable more products to be tested to prevent the under-regulation of hazardous products. And so on. The tapestry of values that is science includes, in short, the values of science's diverse array of stakeholders, and the result is exceedingly complex. What's more, many of these values conflict, with no clear resolutions in sight. So Kevin, the teacher of philosophy students, allows his readers to think through the relevant issues and come to their own conclusions. Indeed, he encourages his readers to do just that by his discussion questions for each chapter at the end of the book and by his vigorous, wonderfully informed, and evenhanded portrayal of the various stakeholders' values and some of the considerations that lie behind them. His approach here, of course, is the approach typical of the best philosophy courses, the approach that makes them so exciting. So, Kevin's book in this respect is like all those old discussions regarding evil demons and trolleys and brains in a vat and the rest that first attracted us to philosophy, although the issues taken up in Kevin's book are very real and the stakes hanging on their resolution are very high.

For science, science policy, and research ethics students, on the other hand, the tapestry of values that Kevin describes can appear more like a nightmare than a dream. Of course, the science portrayed by Kevin's book is a science very much in process - at best, a tapestry of values being woven rather than a tapestry already finished. Still, Kevin's text suggests that the emerging pattern is a bit disheveled and out of kilter, given that the values that make up science are so frequently in conflict with one another and, sometimes, even in conflict with the epistemic values that are also there in the fabric. Worse still, some of these conflicts involve what seem to be clearly unacceptable values - sexist values or racist values or cultural or class biases of one sort or another, for example. So, the tapestry being woven is ugly in places as well as disheveled-in fact quite ugly in quite a number of places.

Kevin emphasizes, however, that while some of the values shaping science have had bad, sometimes even horrendous, effects on both science and society, others have been the stuff of great progress on both fronts. So values are neither science's kiss of death nor its elixir of life. Still, they are powerful, and they can't be ignored. Nor can they be screened out of science. As a result, responsible scientists must be vigilant. They must be on the lookout for the influence of values in their research, and they must be able to assess these values and their influence very carefully, because the stakes can be high. And Kevin's book aims to help scientists to do just that.

To begin with, Kevin carefully sets out the two circumstances in which values might influence scientists' work. The first is when scientists are forced to make decisions in their researchfor example, regarding their choice of topics or concepts or aims or methods-that are not completely grounded in epistemic considerations but instead serve some value or other. The second is when scientists make choices in their research that help them achieve specific social goals. When either of these two circumstances obtains, Kevin explains, scientists are allowing values to shape their research.

But scientists can do this in an entirely appropriate way, according to Kevin. Three steps are all it takes. First, scientists should strive to incorporate in their research not just any values but rather those "values that are representative of major social and ethical priorities." This is Kevin's representativeness condition. Second, scientists should exhibit the details of their research so transparently that whatever values are operating there and whatever influences they are exerting can be detected and evaluated. This is Kevin's transparency condition. And third, this detection and evaluation, this "scrutiny," must be carried out by the right people, that is, by the relevant 
stakeholders, all those individuals somehow affected by or invested in the research. This means that appropriate forms of engagement must be fostered so that the relevant stakeholders can help to identify and reflect on the value influences in question. This is Kevin's engagement condition. When all three conditions are satisfied, Kevin assures us, scientists will be allowing values to shape their research in an appropriate way.

But now, what was a pedagogical strength for philosophy students emerges as a pedagogical weakness for science, science policy, and research ethics students. For, the candidates for the status of "values that are representative of major social and ethical priorities" are left unclear and unjustified. For example, some of the ones mentioned throughout Kevin's book are equal opportunity, protection of the environment, promotion of public health, public welfare, economic growth, and global security. But exactly what these mean, what they enjoin and exclude, and how they are to be justified, are completely unexplained by Kevin. And while that might enliven a philosophy class discussion, the prospects for the same happening with the science, science policy, and research ethics students are far less rosy. After all, these "values that are representative of major social and ethical priorities" were to be the values that would provide guidance to scientists, the values that would ensure that scientists' research was appropriate. And the worry is that almost any kind of research will be found appropriate according to at least one of them in their present undefined state. Indeed, even exorbitantly priced me-too drugs produced by big pharma's scientists can still be said to promote public health. And the most heinous weapons devised by military scientists can still be said to contribute to global security.

I think Kevin thinks that the engagement condition will take care of all this, that the engagement condition is the most fundamental of his three conditions. As he says, the engagement between scientists and other stakeholders "helps to facilitate both of the other conditionstransparency and representativeness-by promoting thoughtful scrutiny of values in science" (15). So Kevin spends a whole chapter spelling out various ways in which the engagement condition might be satisfied, and then he leaves it at that. But, if anything, the engagement condition presupposes the representativeness condition rather than the other way around. After all, the engagement condition broaches such issues as which people's views are to count, whether all these people should be treated equally, whether their views should count as heavily as the scientists' views, what liberties should be taken with the editing or interpreting of their views, and so on-issues that involve ethical considerations of fairness and equality and respect and others as well. And this should come as no surprise. After all, Kevin's engagement condition is part of the new push by many to democratize science, a push obviously powered by ethical and political principles. So, what Kevin needs for his science, science policy, and research ethics students is at least a chapter spelling out the representativeness condition to supplement his chapter on the engagement condition.

What might this chapter include? According to Kevin, "when clear, widely recognized ethical principles are available, they should be used to guide the values that influence science. When ethical principles are less settled, science should be influenced as much as possible by values that represent broad societal priorities" (14-15). So, it may be that Kevin does not even try to spell out his representativeness condition because he thinks there are no widely recognized ethical principles with which to do so. Indeed, the only places in which Kevin explicitly says that there are strong ethical reasons to promote particular values are when he is dealing with equal opportunity and anti-racism. For example, he says:

Given that one of our fundamental social values is to provide equal opportunities for everyone who has the capability to excel in science and mathematics—and given that there are strong ethical reasons to promote this value as well-it turns out that this area of research [that is, race- and gender-related cognitive-differences research, 
especially biologically based cognitive-differences research] should probably not be a priority. (22)

But even here Kevin does not specify the strong ethical reasons that would provide the justification, and he certainly could at least try to do so. He could provide a Rawlsian justification, for example one that makes use of the "veil of ignorance," the approach that rests on the principle that no one deserves his native abilities or her initial starting place in society. Or Kevin could provide a utilitarian justification, or something else instead. He could argue that all these approaches, though very different, end up justifying the same value-which would make a strong case for the value. Or he could argue that one of these approaches, the most defensible one, is the one that furnishes the authority for the value. Note that the engagement condition involves relevant stakeholders providing arguments for their input. It is high time we philosophers of science did the same.

Should Kevin go this route, he would at least begin to make a case for many of his "values that are representative of major social and ethical priorities" that right now he leaves unjustified. For example, choosing to go the Rawlsian route, he could make use of Rawls's fair equal opportunity principle, the principle that requires that all those with the same native abilities be provided with the same social opportunities for success in society. This principle would justify Kevin's scienceand mathematics-related equal opportunity value. But it would also open the door to other justifications that Kevin needs. For example, Rawls points out that, although the fair equal opportunity principle is a corrective for unfair class and other social disadvantages in society, it does nothing to correct for the disadvantages people have dealt to them by nature-what Rawls calls the natural lottery. To correct for these disadvantages, Rawls argues that we need some kind of an effective basic welfare system or, more generally, a system that benefits and prevents harms to the least advantaged in society. Such a system would justify the values motivating many of the scientists and policymakers whose activities Kevin describes, while it would exclude as unjustifiable other values that Kevin also describes (such as those that shape much of the research and practices of the pharmaceutical, chemical, and tobacco industries).

Of course, much more would need to be done by Kevin to define and justify all those values that are in fact representative of major social and ethical priorities, or that ought to be, and to exclude all the counterfeits. But even a preliminary analysis and assessment of the values described in his book would help to bring the actual tapestry of values in science closer to the beautiful one Kevin envisions.

\section{Literature cited}

Brown, Matthew J. 2018. "Weaving Value Judgment into the Tapestry of Science.” Philosophy, Theory, and Practice in Biology 10 (10). https://doi.org/10.3998/ptpbio.16039257.0010.010.

Douglas, Heather. 2018. "From Tapestry to Loom: Broadening the Perspective on Values in Science." Philosophy, Theory, and Practice in Biology 10 (8). https://doi.org/10.3998/ptpbio.16039257.0010. 008.

Elliott, Kevin C. 2018a. "Précis of A Tapestry of Values: An Introduction to Values in Science." Philosophy, Theory, and Practice in Biology 10 (7). https://doi.org/10.3998/ptpbio.16039257.0010.007.

Elliott, Kevin C. 2018b. “A Tapestry of Values: Response to My Critics.” Philosophy, Theory, and Practice in Biology 10 (11). https://doi.org/10.3998/ptpbio.16039257.0010.011. 
(C) 2018 Author(s)

This is an open-access article distributed under the terms of the Creative Commons AttributionNonCommercial-NoDerivatives 4.0 International license, which permits anyone to download, copy, distribute, or display the full text without asking for permission, provided that the creator(s) are given full credit, no derivative works are created, and the work is not used for commercial purposes.

ISSN 2475-3025 